\title{
Student Perceptions towards Flipped Learning in Software Engineering Course
}

\author{
Teduh Dirgahayu \\ Universitas Islam Indonesia \\ Yogyakarta, Indonesia
}

\begin{abstract}
Flipped learning is a pedagogical approach that creates a dynamic and interactive learning environment. It has been used in Software Engineering (SE) course to give students more time for doing their work under teacher supervision during in-class learning. This paper presents student perceptions toward the use of flipped learning in SE course. The results indicate that this approach gives a good impact on students' understanding and practical skills. The perceptions were measured on several aspects, i.e. (i) the suitability of flipped learning for the course, (ii) student's engagement to the course, and (iii) the quality of teacher supervision during the in-class time. Students indicate positive perceptions on all those aspects.
\end{abstract}

Keywords-Perceptions, flipped learning, software engineering

\section{INTRODUCTION}

There is a lot of model of learning that has been implementing in the software engineering courses. The courses should be a based on the standard competency that related to the student's ability to gain knowledge. There are many models of learning involving the competency that has been developed by some experts through research and also from the development conceptional models. However, when the learning models were implemented some of the results shows there is infective or not adaptable to the students because of the ability of the lecturer or the teachers in transforming their knowledge.

Based on this learning model is translated, that this innovation of the learning process make students should easily gain more knowledge and more adaptable to changing the lecturer knowledge; the innovation models also can be translated or planning to improve the students understanding the theory in the courses through empirical experience.

The learning models of software engineering courses are developed to improve the activity of the students and also the ability of the students to develop and create efficiency in the learning process. Moreover, at the same time, improve the student's competency and responsibility and students participating in the learning process.

Learning is more valuable when the students have selfefficacy to improve the student's innovation in the learning process and create more flexible learning models and learning tools based on the student centre model of education, than learning based on the teacher centre.
To improve the quality of learning, so much to do, among other things, by developing emotional intelligence, developing creativity in learning, disciplining students with love of science, generating the spirit of learning, solving problems, utilising educational resources, and involving the learning community.

Software engineering (SE) is a knowledge course to learn in an undergraduate degree program in Computer Science [1]. It includes, among others, the topics of requirements analysis and software design. SE course was aimed at developing students' competencies on those topics as they are critical for software success. In the Department of Informatics in Universitas Islam Indonesia, the development of these skills is given $43 \%$ of total time in SE course.

In this course, the students are working in teams on semester projects. Students analyse and create a model the software requirements and designs in standard modelling languages. Further, they document the results in specifications, i.e. software requirement specification (SRS) and software design description (SDD).

In the previous years, the teachers presented and explained concepts and principles of requirements analysis and software design during in-class lectures. The teachers also introduced diagrams to model the results of analysis and design activities. The teachers then supervised students in applying the concepts and principles on their projects. However, time available for students to work under teachers' supervision in class was very limited. Hence students had to continue to work unsupervised off the class.

From five years' experience in teaching SE course, the author has learned that the insufficient time for students to work under teacher supervision leads to low-quality specifications. Errors was an easily found in their specifications.

Last year the author used flipped learning to give students more time for doing their work under teacher supervision in class. The results indicate that flipped learning gave a real impact on students' practical skills.

The objective of this paper is to present student perceptions toward the learning approach. This opinion is important for improving the way the method is using. 


\section{LITERATURE REVIEW}

Innovations in learning approaches have been developed to make effective the learning process. Flipped learning is an innovation in which learning process that is traditionally doing in class and off class flipped, i.e. content delivery is doing off class; while discussion, case studies, or project work doing in class [2].

Flipped learning reclaims in-class time for individuals that are ready for group learning [3]. Individual learning before inclass time is therefore critical. To accommodating individual learning, the contents are usually providing in videos. Using the videos, students have their control over time, place and learning pace [4].

Flipped learning can enhance student's engagement with the course content. This engagement would drive students to participate during group learning in-class time [2] actively. Active participation indicates that students move into deep learning from which students can explain connections between topics of the course [3].

Flipped learning has been used in higher education [5], e.g. calculus [6], chemistry [7], economics [8], [9], health [2], history [10], nursing [11], psychology [12], and social [13].

Teachers that had applied this learning approach asked their students' perceptions about the approach, e.g. [8], [2], [10]. These opinions give some valuable insights for the teachers that want to continue to use the learning approach.

Roach applied flipped learning in microeconomics course. He surveyed the student's perceptions on (i) their impression about the learning method, (ii) their perceived level of interaction, (iii) their reaction to the approach and types of video lectures, and (iv) whether they watch the video lectures[8]. The results indicated that students have good perceptions on the learning approach.

Student perceptions were also surveyed after the application of flipped learning in nutrition course [2]. The survey results indicated, among others, that (i) students prefer to watch a video rather than straight lecture, (ii) students do not prefer lecture rather than in-class activities, and (iii) students do not feel disconnected without teachers' presence during an online class.

A survey about flipped learning was done by [10] in his history course. The survey results indicated that (i) students prefer to learn with flipped learning, (ii) students had learned more with this learning approach, and (iii) in-class discussion is the most efficient assignment to learn the course content.

\section{METHOD}

The author taught SE class using flipped learning for the topics of requirement analysis and software design only. The author followed a recommendation saying that flipped learning should start from small and learn from it [14].

Content delivery was done using videos. The author created videos online using Google Hangouts On Air and uploaded them to YouTube. Those videos were to accommodate individual learning before in-class time.
During the in-class time, students in teams worked on their projects under teacher supervision as in [13]. The projects cannot be finishing in the class. It is because the students must have complete the projects in off-class. In the end, all teams had to present their specifications in class. As the teacher, the author gave feedback for improving the specifications before grading.

The use of flipped learning gave a real impact on students' practical skills. Explanations for this result are as follows.

- Students got sufficient time to work on their project under teacher supervision.

- Students got feedbacks from the teacher and enough time to elaborate the feedback before grading.

At the end of the use of flipped learning, the author distributed questionnaire to collect student perceptions on

- Suitability of flipped learning for the course

- Students engagement to the course

- The quality of teacher supervision during the in-class time.

The questionnaire uses Likert Scale ( 1 = strongly disagree, $2=$ disagree, $3=$ neither agree or disagree, $4=$ agree, and $5=$ strongly agree).

\section{RESUlTS}

Most of the respondents were agree about the suitability of flipped learning for the course (Figure 1). The average score is 3.9 (tends to agree), which means that students considered that flipped learning is suitable for the course. Improvement is, however, needed to make this learning approach appropriate for the course.

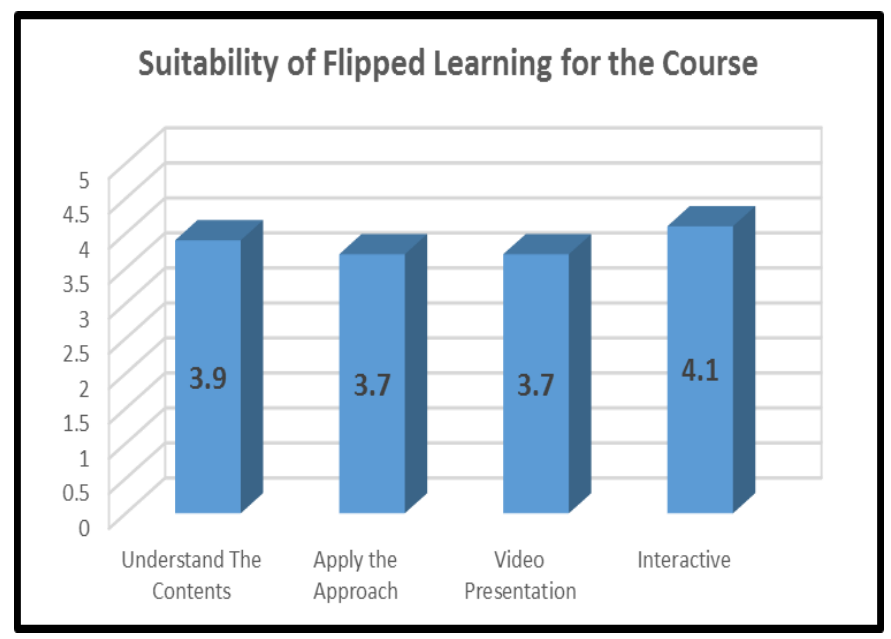

Fig. 1. The Perception of suitability of flipped learning for the course

The perception on student's engagement to the class was shown in Figure 2. 


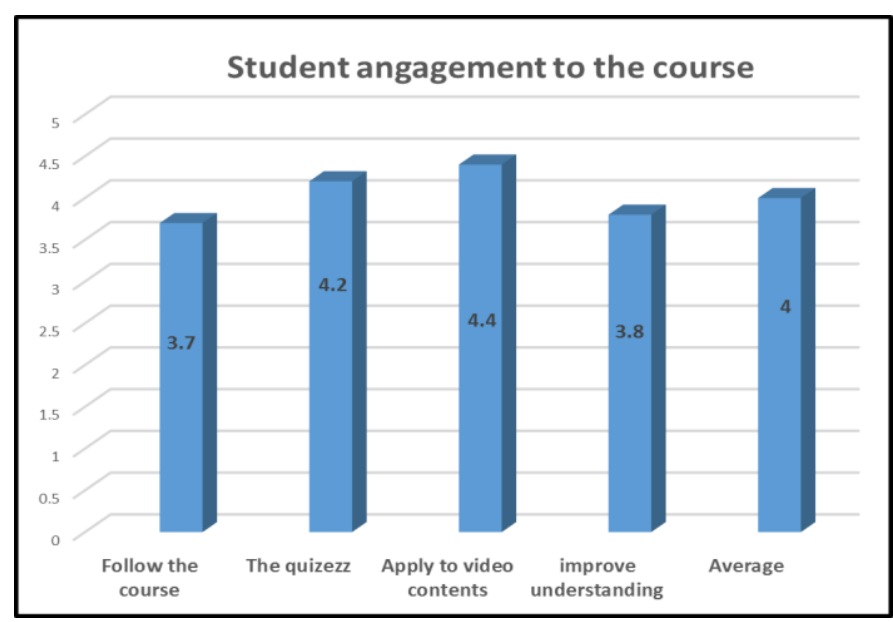

Fig. 2. The perception of student's engagement to the course

Figure 2, indicates that the average of students engagement is 4.0. This means that students are engaging in the class rooms. The students also agree that they are following the courses to improve their understanding. More over the student's engagements is also stated they can be enhanced their knowledge by seeing the video instructions.

The perception of the quality of teacher supervision during the in-class. The average score is 4.4 (between agree and strongly agree), which means that groups considered that the teacher supervises them well when they work on their projects.

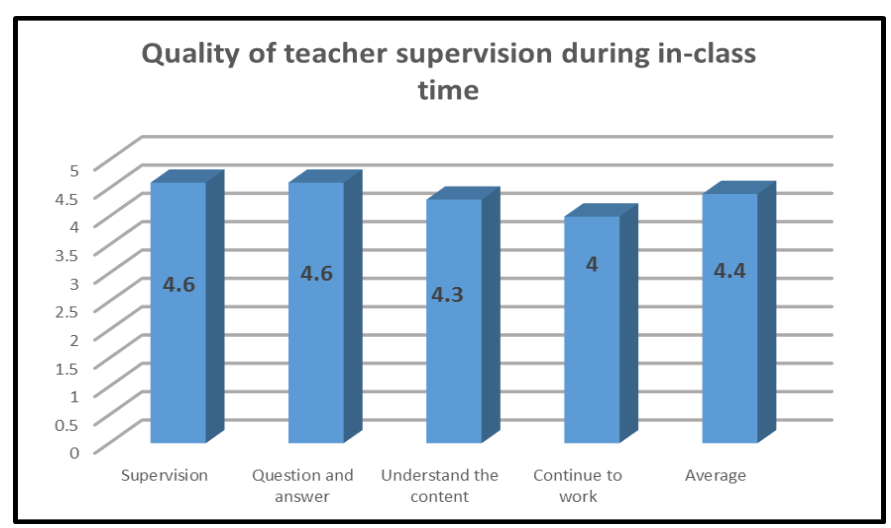

Fig. 3. The quality of teacher supervision during the in-class.

The figure 3 shows that the quality of the teacher supervision during the class time is very high. The perception of the students indicates that the average of monitoring level is 4.4 and the other criteria also suggest that the value of the understand the content is 4.3 that more than continue to work is 4.0. This means that the student believes they are under excellent supervision.

The survey presented in this paper is different from but inspired by, the study mentioned in Section 2, i.e. [8], [2], [10]. Each survey was designed to measure different aspects of student perceptions. Nevertheless, the results of all polls, including this survey, confirm positive perceptions towards the learning approach.

\section{CONCLUSION}

We have presented student perception towards flipped learning in SE course. Perceived aspects to the success of the use of flipped learning are (i) the suitability of the learning approach for the course, (ii) student's engagement to the course, and (iii) quality of lecture supervision during the inclass time. The significance of each aspect of students' practical skills shall be further research.

\section{ACKNOWLEDGMENT}

The author thanks to the Board of Academic Development UII for funding this research. The author al-so thanks the students of his SE course in UII for participating in this research.

\section{REFERENCES}

[1] A. C. M. J. T. Force, "Computer science curricula 2013: Curriculum guidelines for undergraduate degree programs in computer science," Technical report, Association for Computing Machinery (ACM) IEEE Computer Society, 2013.

[2] M. B. Gilboy, S. Heinerichs, and G. Pazzaglia, "Enhancing student engagement using the flipped classroom," J. Nutr. Educ. Behav., vol. 47, no. 1, pp. 109-114, 2015

[3] J. Bergmann and A. Sams, Flipped learning: Gateway to student engagement. International Society for Technology in Education, 2014.

[4] C. Steeples, P. Goodyear, and H. Mellar, "Flexible learning in higher education: the use of computer-mediated communications," Comput. Educ., vol. 22, no. 1-2, pp. 83-90, 1994.

[5] J. O'Flaherty and C. Phillips, "The use of flipped classrooms in higher education: A scoping review," Internet High. Educ., vol. 25, pp. 85-95, 2015.

[6] R. Talbert, "Flipped Calculus: A Gateway to Lifelong Learning in Mathematics," in Best Practices for Flipping the College Classroom, J. B. Waldrop, Ed. USA: Routledge, 2016, pp. 44-54.

[7] C. Yestrebsky, "Flipping a Large First-Year Chemistry Class: SameSemester Comparison with a Traditionally Taught Large-Lecture Class," in Best Practices for Flipping the College Classroom, J. B. Waldrop, Ed. USA: Routledge, 2016, pp. 17-28.

[8] T. Roach, "Student perceptions toward flipped learning: New methods to increase interaction and active learning in economics," Int. Rev. Econ. Educ., vol. 17, pp. 74-84, 2014.

[9] K. Sauer, "Don't Flip Out: Inverting the Intermediate Microeconomics Classroom," in Best Practices for Flipping the College Classroom, J.B. Waldrop, Ed. USA: Routledge, 2016, pp. 101-117.

[10] D. Murphree, "Taking Ownership of the Past: Flipping the History Course as a Means of Increasing Student Engagement," J. B. W. \& M. A. Bowndon, Ed. Routledge, 2016, pp. 55-68.

[11] J. B. Waldrop and M. A. Bowdon, Best Practices for Flipping the College Classroom. Routledge, 2016.

[12] A. Thompson, C \& Martin, “A. Best Practices for Flipping the College Classroom: Elements of Psychology, an Introductory Psychology Course at the University of Oklahoma," in Best Practices for Flipping the College Classroom, J. B. Waldrop, Ed. USA: Routledge, 2016, pp. 69-86.

[13] T. Wanner and E. Palmer, "Personalising learning: Exploring student and teacher perceptions about flexible learning and assessment in a flipped university course," Comput. Educ., vol. 88, pp. 354-369, 2015.

[14] A. Steed, "The flipped classroom," Teach. Bus. Econ., vol. 16, no. 3, p. 9, 2012. 